\title{
LA CALIDAD REGULATORIA EN EL SERVICIO PÚBLICO DE ACUEDUCTO Y AGUA POTABLE. UN ANÁLISIS A PARTIR DE LA IMPLEMENTACIÓN DE LOS OBJETIVOS DE DESARROLLO SOSTENIBLE (ODS)
}

\author{
QUALITY REGULATORY IN THE PUBLIC DRINKING WATER SYSTEMS. AN ANALYSIS \\ BASED ON THE SUSTAINABLE DEVELOPMENT GOALS (SDG) IMPLEMENTATION
}

\section{William Iván Gallo Aponte}

\author{
Abogado por la Universidad Externado de Colombia; \\ Miembro fundador de la Red Iberoamericana Juvenil de Derecho Administrativo - México; \\ Asistente de investigación en el Departamento de Derecho de Medio Ambiente de la \\ Universidad Externado de Colombia y abogado en el área de litigios de la firma Moreno Servicios Legales. \\ Ponente invitado en Ecuador, Perú, Brasil, Chile, México, etc \\ E-mail: williamg.aponte@gmail.com
}

Convidado

RESUMEN. La necesidad de abastecer los núcleos poblacionales para la satisfacción de necesidades básicas corresponde con una priorización a la que debe atender la función administrativa en la prestación de los servicios públicos. En consonancia con ese propósito, y frente a la problemática que actualmente atraviesa el recurso hídrico, los países han comprometido su esfuerzo en lograr el desarrollo sostenible bajo una visión reduccionista de las problemáticas sociales. Es ahí donde las prácticas de mejora regulatoria pueden contribuir desde la planeación, ejecución y evaluación a alcanzar de manera efectiva los Objetivos de Desarrollo Sostenble y así lograr la satisfacción del interés general.

Palabras Clave: Agua Potable; Calidad Regulatoria; Servicio Público; Objetivos de Desarrollo Sostenible; Interés General.

\begin{abstract}
The need to provide urban and rural centers for the satisfaction of basic necessities, is appropriate with a prioritization in the administrative function for the public services deliver. In line with this purpose, and before the water resource problem, different countries have committed their efforts to get the sustainable development based on reductionist vision of social issues. This is where the Regulatory Practice Improvement could make a vital contribution to achieves these Sustainable Development Goals and the general and public interest satisfaction.
\end{abstract}

Key Words: Potable Water; Quality Regulatory; Public Drinking Water Systems; Sustainable Development Goals, Public Interest. 
SUMARIO: Introducción; 1 El Servicio Público de Acueducto y Agua Potable; 2 El "Agua Límpia y Saneamiento" como objetivo de Desarrollo Sostenible: Hacia la Garantía en el Suministro de Agua Potable; 2.1 Los Objetivos de Desarrollo Sostenible (Ods) y su Implementación en el Ordenamiento Jurídico Colombiano. Consideraciones Generales. 2.2 Garantía para la Disponibilidad de Agua y su Gestión Sostenible y el Saneamiento para todos: un objetivo en Construcción; 3 La Calidad Regulatoria y el Suministro de Agua Potable y Saneamiento. 3.1 La Agenda Regulatoria en el Suministro de Agua Potable y Saneamiento. 3.2 El Análisis de Impacto Regulatorio para la Formulación de una Adecuada Política de Acueducto y Agua Potable; 3.2 La Abogacía de la Competencia y la Evaluación de Impacto Ex Ante en el Servicio Público de Acueducto y Agua Potable; 3.3 Evaluación de Impacto Ex Post y su necesidad para el Servicio Público de Acueducto y Agua Potable; Conclusiones; Bibliografía y Fuentes de Información.

\section{INTRODUCCIÓN}

"La escasez de agua afecta a más del $40 \%$ de la población mundial, una cifra alarmante que probablemente crecerá con el aumento de las temperaturas globales producto del cambio climático" (PNUD). De esta manera, Naciones Unidas presenta una de las problemáticas, sino la mayor, que más preocupa en el mundo. Es así como se han generado múltiples esfuerzos nacionales e internacionales para combatir la escasez y garantizar en su totalidad el suministro de agua potable y saneamiento básico.

Los esfuerzos aún no han sido suficientes, desde la Conferencia de las Naciones Unidas sobre el Agua en 1977 (Naciones Unidas, 1977), hasta los últimos acuerdos clave que incluyen la Agenda 2030 sobre Objetivos de Desarrollo Sostenible, el Acuerdo de Paris 2015 dentro del Marco de la Convención de las Naciones Unidas sobre el Cambio Climático, entre otros. Se ha tratado de dar alcance, desarrollo y ejecución a diferentes planes y proyectos relacionados con la garantía del agua potable.

La adopción de compromisos internacionales por parte de los países, se traduce en la implementación de nuevos retos y estándares para la prestación universal, adecuada y de calidad, del servicio público de acueducto y agua potable. En este sentido, desde el punto de vista interno, es el ejercicio intervencionista del Estado, uno de los escenarios más adecuados para concretar tales propósitos y combatir la problemática que atraviesa el recurso hídrico.

Con el ánimo de brindar herramientas que contribuyan a una mejora en la implementación y seguimiento de proyectos y políticas relacionadas con el recurso hídrico, el presente escrito tiene como objetivo hacer un análisis del suministro del agua como servicio público a partir de la implementación de los Objetivos de Desarrollo Sostenible (ODS), pues sobre este llamado universal, las naciones deben dirigir sus esfuerzos para brindar paulatinamente una mejora en la calidad de vida de sus ciudadanos. Asimismo, promover las mejoras regulatorias como una herramienta de tendencia global, que garantice el suministro de agua potable, las condiciones adecuadas de saneamiento y la mejora en la prestación del servicio. En ese sentido, dentro de este análisis, también será objeto identificar la posible correspondencia y efectividad de la calidad regulatoria con la prestación del servicio público de acueducto y agua potable.

Para cumplir el objetivo, desde un punto de vista metodológico, el presente escrito parte de un análisis sobre el servicio público de Acueducto y Agua Potable en Colombia, identificando su marco legal y la institucionalidad alrededor del mismo. En segundo lugar, se identifica "El agua limpia y saneamiento" como Objetivo de Desarrollo Sostenible. A partir de ahí, se desarrollan unas 
consideraciones generales sobre los ODS y su implementación en el ordenamiento jurídico colombiano, así como la concreción de la garantía para la disponibilidad de agua y su gestión sostenible en Colombia con algunas experiencias comparadas. Finalmente, se propone unas ideas alrededor de la calidad regulatoria en el suministro de agua potable y saneamiento, a partir de herramientas que llevan a la mejora, entre ellas, la agenda regulatoria, el Análisis de Impacto Regulatorio, la abogacía de la competencia y las evaluaciones de impacto ex ante y ex post. Es necesario advertir, que son múltiples los instrumentos de mejora regulatoria que pueden contribuir al sector, sin embargo, sin restarle importancia a figuras como la expedición normativa o la consulta pública, el presente escrito se limita a unas figuras en concreto.

\section{EL SERVICIO PÚBLICO DE ACUEDUCTO Y AGUA POTABLE}

El marco legal de los servicios públicos establece dentro de su ámbito de aplicación el servicio público domiciliario de acueducto o de agua potable (ley 142, 1994, art. 1). Éste se define como "la distribución municipal de agua apta para el consumo humano, incluida su conexión y medición. (...) Las actividades complementarias tales como captación de agua, su procesamiento, tratamiento, almacenamiento, conducción y transporte" (ley 142, 1994, art. 14).

A sabiendas de la extensión del concepto de servicio público de agua potable, para efectos del presente escrito, se delimitará su objeto a la distribución de agua apta para el consumo humano. En este sentido, la prestación del servicio se enmarca en "la necesidad de abastecer los núcleos poblacionales, ya sean estos urbanos o rurales, a fin de que puedan satisfacer sus necesidades básicas" (García, 2017a, p. 139).

Del mismo modo, la prestación se justifica en "la exigencia de cubrir necesidades sociales y de salud pública, y la urgencia por responder a la creciente demanda del recurso por las poblaciones, las cuales requieren disponer de agua en sus casas de modo continuo" (García, 2017b, p. 140). Tanto la exigencia como la necesidad requieren una manifestación de actividad administrativa que comprende no solo su cobertura o satisfacción, sino también, atender a criterios de eficiencia, universalidad y transparencia.

La importancia no es minúscula, más aún, cuando se trata quizás del servicio público por excelencia (Amaya, 2007, p. 113). Por esta razón, son múltiples las variables para su entendimiento, unas con fundamento en el carácter económico del agua, otras con relación al agua como recurso natural renovable, y transversal a las anteriores, el derecho humano al agua y a gozar de un ambiente sano (Amaya Arias \& Amaya Navas, 2017, p. 87-89). Sin embargo, consideramos que, para la prestación adecuada de los servicios públicos, es necesario articular estas y otras variables porque no solo resultan dependientes, sino que, al no ser excluyentes, entenderlas en conjunto permiten lograr en mayor medida la satisfacción de los fines estatales, concretamente, el servicio a la comunidad y la garantía de los derechos constitucionales.

Por ejemplo, a manera de ilustración, el reconocimiento del mínimo vital de agua potable (MVAP) a ciertas poblaciones, requiere no sólo un diagnóstico desde el punto de vista financiero, que involucra generalidades como la suspensión por la falta de pago, hasta su alivio a través de subsidios. También, requiere de un análisis desde el derecho, pues lleva consigo la satisfacción y la garantía de la vida, la igualdad, la dignidad o la salud (Corte Constitucional, C-546, 2009).

Introducida la definición del servicio público domiciliario de acueducto y de agua potable, la delimitación y justificación en su prestación, así como una propuesta para su entendimiento. Es necesario hacer referencia a la competencia de las autoridades administrativas para su prestación eficiente. 
En este sentido, el artículo 5 de la ley 142 de 1994, señala que,

Es competencia de los municipios en relación con los servicios públicos, que ejercerán en los términos de la ley, y de los reglamentos que con sujeción a ella expidan los concejos: 5.1. Asegurar que se presten a sus habitantes, de manera eficiente, los servicios públicos domiciliarios de acueducto, alcantarillado, aseo, energía eléctrica, y telefonía pública básica conmutada, por empresas de servicios públicos de carácter oficial, privado o mixto, o directamente por la administración central del respectivo municipio (...).

La disposición anterior obedece al mandato constitucional general a través del cual se establece que, "es deber del Estado asegurar su prestación eficiente a todos los habitantes del territorio nacional" (Const., 1991a, art. 365). Lo cual, desde la descentralización y autonomía de sus entidades territoriales, corresponde al municipio como entidad fundamental de la división políticoadministrativa del Estado, prestar los servicios públicos que determine la ley" (Const., 1991, art. 311). Sin embargo, la constitución prevé que la prestación podrá ser "directa o indirectamente, por comunidades organizadas, o por particulares" (Const., 1991b, art. 365). No obstante, será el Estado quien mantendrá la regulación, el control y la vigilancia de dichos servicios.

La pluralidad de actores que pueden intervenir en la prestación del servicio se enmarca dentro de un régimen de "libre competencia" o "libertad de entrada", atendiendo al artículo 333 de la Constitución Política de Colombia. De acuerdo con esto, el artículo 22 de la ley 142 de 1994 señala que, si la empresa de servicios públicos (en adelante ESP) se encuentra debidamente constituida, no requiere un permiso para desarrollar su objeto social más allá de obtener la concesión, el permiso o la licencia correspondiente por parte de la autoridad competente, para poder operar.

Lo anterior se traduce, como lo ha indicado la Superintendencia de Servicios Públicos Domiciliarios (en adelante SSPD), en que "la libertad de entrada supone, de alguna manera, una forma de promoción de la competencia que permite que los usuarios tengan la posibilidad de elegir libremente el prestador del servicio público entre una gama de competidores" (SSPD, 2009a).

Aún teniendo en cuenta que existe un régimen de libertad de entrada, desde el punto de vista del usuario y los agentes que interactúan en el mercado, esa posibilidad de elección se ha condicionado a un abuso de la posición de dominio o en términos generales a una restricción en el ámbito de su competencia. Por ejemplo, la Superintendencia de Industria y Comercio ha sancionado eventos en los cuales se distribuye y vende agua en bloque con la intención de excluir un competidor en el mercado del acueducto. ${ }^{1}$

Por su parte, la posibilidad de que la prestación sea directamente por cada municipio, por comunidades organizadas" ${ }^{2}$ o por particulares, dependerá de "las características técnicas y económicas del servicio y las conveniencias generales lo permitan y aconsejan" (SSPD, 2009b). Lo que corresponde a una evaluación de política de hacienda pública, pero sobre todo de infraestructura y su financiación. Con relación a la conveniencia que determina la prestación del servicio, la ley 142 de 1994 establece unos límites, entre ellos, el interés general y el propósito de cobertura de los servicios públicos a las personas de menores ingresos, lo que comúnmente se han denominado áreas de servicio exclusivo (ley 142, 1994a, art. 40).

\footnotetext{
${ }^{1}$ Tal es el caso de la sanción impuesta por la Superintendencia de Industria y Comercio (en adelante SIC) a la empresa de Acueducto y Alcantarillado de Bogotá por "abusar de suposición de dominio en el mercado de venta de agua en bloque en Bogotá con al intención de excluir u obstruir la prestación del servicio de acueducto que COOPJARDIN prestaba en la zona de Guaymaral en el norte de Bogotá (...) la conducta consistió en la instalación de una platina reductora de caudal y una válvula reductora de presión". (SIC, 2018).

${ }^{2}$ Debe tenerse en cuenta que dentro de las posibilidades para la prestación del servicio público se tiene en cuenta Empresas Industriales y Comerciales del Estado, Sociedades de Economía Mixta, Organizaciones Solidarias, etc.
} 
Las áreas de servicio exclusivo suponen que la entidad o las entidades territoriales competentes, podrán establecerlas mediante invitación pública, con la finalidad de que ninguna otra empresa de servicios públicos pueda ofrecer los mismos servicios en la misma área durante un tiempo determinado (ley 142, 1994b, art. 40). Sin embargo, esta limitación debe atender a criterios de precisión y niveles de calidad. Es pertinente señalar que la conveniencia de la inclusión de estas áreas estará supeditada a la verificación de la definición de la Comisión de Regulación respectiva, en este caso, la Comisión de Regulación de Agua Potable y Saneamiento Básico (en adelante CRA). (ley 142, 1994c, art. 40).

Con todo el régimen de libertad y la conveniencia para la prestación directa o no de los servicios públicos, es importante señalar que el Consejo de Estado ha precisado que la prestación directa del servicio público por parte de los municipios es la regla general. Y que en el caso de que no hubiera otra entidad que los pudiera prestar, o que el mercado lo impida, el Estado en aras de asegurar su prestación continua, eficiente y universal, deja en libertad la capacidad de su abastecimiento (Consejo de Estado, Sección Tercera, Exp. 27763, 2005).

Una vez descrita la competencia y su margen de maniobrabilidad, la forma a través de la cual se presta el servicio público domiciliario de acueducto o de agua potable, tiene relación con los aspectos técnicos de su distribución, conexión y medición. Sin embargo, es necesario determinar que las actividades complementarias al servicio deben estar estipuladas bajo un marco regulatorio general que permita al Estado una facilidad en el control adecuado de la prestación del servicio, y el establecimiento de herramientas para que el mercado funcione acorde con los objetivos económicamente deseables (Stapper, 2009, p. 23).

Con todo lo anterior, es necesario dejar presente lo señalado por el mexicano Fernández Ruiz (2016, p. 247-249), al indicar, que la actividad relativa al servicio público es toda actividad técnica destinada a satisfacer una necesidad general, que tiene sujeción al "régimen exorbitante del derecho privado", puesto que, se desarrolla en un marco de desigualdad entre los principales intereses involucrados en el servicio público. Esto es, no solo desde el punto de vista de los usuarios, sino también desde los intereses del prestador, los intereses de la sociedad y los intereses del Estado.

Así pues, la forma de la prestación del servicio público más allá de la técnica debe atender a la satisfacción del interés de los múltiples partícipes en el ejercicio de esta actividad. En otras palabras, además de la gran importancia del usuario en la actividad prestacional, el mejoramiento de su calidad de vida, el interés económico del prestador existe un interés general que "pretende garantizar la sostenibilidad ambiental" (Amaya, 2018, p. 22) y la protección y conservación de los recursos naturales renovables (Decreto Ley 2811, 1974, art. 3) como interés de la sociedad y del Estado.

Desde el punto de vista del control y la vigilancia de la prestación del servicio público domiciliario de acueducto o de agua potable, la ley 142 de 1994 establece dos tipos de control, uno social y uno institucional. El primero de ellos, se realiza a través de un "Comité de Desarrollo y Control Social" (ley 142, 1994, art. 62), compuesto por usuarios, suscriptores o suscriptores potenciales ${ }^{3}$, con la finalidad de proponer a las Empresas de Servicios Públicos Domiciliarios planes y programas dentro del ejercicio de la actividad, solicitar la modificación o reforma de las decisiones en materia de estratificación, estudiar y analizar los subsidios que concede el municipio a los usuarios de bajos ingresos, etc (ley 142, 1994, art. 63). Estos comités pueden contar con la participación de entidades

\footnotetext{
${ }^{3}$ Entiéndase suscriptor como la persona natural o jurídica con la cual se ha celebrado un contrato de condiciones uniformes de servicios públicos. Suscriptor Potencial, como la persona que ha iniciado consultas para convertirse en usuario de los servicios públicos y usuario, quien es la persona que se beneficia de la prestación de un servicio (Liga de Consumidores de Bogotá) (SSPD, 2006, p. 25).
} 
administrativas con la finalidad de concertar de manera efectiva el diseño y funcionamiento de las políticas relacionadas con la prestación del servicio (ley 142, 1994, art. 65) (Ley 1437, 2011, art. 3.6).

Por otro lado, el control y la vigilancia institucional está conformada a su vez por un control administrativo, uno disciplinario y otro fiscal. Es menester anticipar que se dará prevalencia al control administrativo, en tanto lo que se pretende es analizar la prestación del servicio en conjunto, más allá de la actuación del servidor público que pertenece al prestador. Por otro lado, que este control es diferente a los medios de control jurisdiccionales dispuestos por el Código de Procedimiento Administrativo y de lo Contencioso Administrativo (en adelante CPACA), los cuales han sido establecidos para ejercer el derecho de contradicción frente a los actos de la administración.

Bajo ese entendimiento, el control y la vigilancia administrativa al Servicio Público Domiciliario de Acueducto y Agua Potable, radica en cabeza del hoy Ministerio de Vivienda, Ciudad y Territorio, en cuyas funciones se establece, la identificación de las fuentes de financiamiento para el servicio público y la elaboración de los planes de expansión de la cobertura, entre otros (ley 142, 1994a, art. 67). Aparentemente, con las funciones descritas no hay evidencia de un control a la prestación del servicio. Sin embargo, por virtud de la ley, la titularidad del control administrativo está en cabeza del presidente, los ministros y los directores de Departamento Administrativo, el cual se orienta a constatar y asegurar que las actividades administrativas y funciones de los organismos y entidades del sector administrativo "se cumplan en armonía con las políticas gubernamentales" (Ley 489, 1998, art. 103-105).

En desarrollo de lo anterior, hace parte del sector (Ley 489, 1998, art. 42) para el control administrativo del Servicio Público de Acueducto y Agua Potable, la Superintendencia de Servicios Públicos Domiciliarios, a través de la cual se ejerce la función de inspección, vigilancia y control de las entidades que presten servicios públicos domiciliarios (ley 142, 1994, art. 75). Esto es, vigilar y controlar el cumplimiento de las leyes y actos administrativos a los que estén sujetos quienes presten servicios públicos, el cumplimiento de los contratos, los subsidios presupuestales de la Nación, sancionar la violación al régimen legal y reglamentario, entre otras (ley 142, 1994, art. 79). Por otro lado, dentro del sector se encuentran también las comisiones de regulación, en concreto, la de Agua Potable y Saneamiento Básico, la cual funge como Unidad Administrativa Especial (ley 142, 1994, art. 69). Lo particular de esta creación, es que la misma ley 142 la adscribe al Ministerio de Vivienda, Ciudad y Territorio ${ }^{4}$, además, el Decreto 2474 de 1999 en su artículo primero, contempla que esta comisión está integrada también por el Ministro de Salud, el ministro del Medio Ambiente y Desarrollo Sostenible y el director del Departamento Nacional de Planeación (en adelante DNP). Sin embargo, es cuestionable que a través del mencionado Decreto se restringa a la SSPD una participación limitada en la Comisión de Regulación, pues puede asistir con voz, pero sin voto, siendo esta una de las entidades más importantes en la estructuración del sector para la adecuada prestación del servicio. ${ }^{5}$

Dentro de las funciones de la CRA se encuentran unas generales y específicas determinadas por la ley 142 (1994, art. 73-74), dentro de ellas, preparar proyectos de ley relativos al sector, definir los criterios de eficiencia y desarrollar indicadores y modelos para la gestión financiera de las empresas de servicios públicos, funciones relativas a evitar cualquier conducta contraria a la libre

\footnotetext{
${ }^{4}$ En su idea original, Ministerio de Desarrollo.

${ }^{5}$ Véase también la limitación en el artículo 4 del Decreto 2882 de 2007, por el cual se aprueban los estatutos y la reglamentación de la Comisión de Agua Potable y de Saneamiento Básico- CRA.
} 
competencia de los prestadores, establecer en que eventos es necesario la realización de obras, instalaciones y operación de equipos destinados a la prestación del servicio de acueducto.

Las funciones específicas también están determinadas a través del (Decreto 2882, 2007, art. 6). Dentro de éste se encuentra, establecer el orden de prioridad y de ejecución de los trabajos regulatorios para la prestación del servicio, aprobar los planes de acción y las agendas regulatorias, de conformidad con la normatividad vigente, entre otras.

Con todo, la manifestación del Servicio Público de Acueducto y de Agua Potable como actividad administrativa, representa un mecanismo para gestionar una "respuesta frente al crecimiento demográfico y al decrecimiento correlativo de las fuentes hídricas" (Amaya, 2018, p. 155), garantizar la dignidad humana (Corte Constitucional, T-881, 2002), conservar los recursos naturales, pues en últimas, el agua es la principal fuente de vida. Su consideración como un Objetivo de Desarrollo Sostenible (en adelante ODS) y la necesidad de adecuar una calidad en su política regulatoria, serán objeto de los siguientes apartes.

\section{EL “AGUA LÍMPIA Y SANEAMIENTO" COMO OBJETIVO DE DESARROLLO SOSTENIBLE: HACIA LA GARANTÍA EN EL SUMINISTRO DE AGUA POTABLE}

Los Objetivos de Desarrollo del Milenio (ODM) "se crearon como una hoja de ruta para poner en marcha la Declaración del Milenio, con base en los valores y principios acordados por los Estados Miembros (...) orientados a la reducción de la pobreza y a la mejora de las vidas de las personas de pocos recursos" (Naciones Unidas). Llegado el plazo proyectado a inicios del presente siglo, los resultados mostraron un escenario que incentivó a la comunidad internacional a tomar la experiencia y acordar unas nuevas metas con visión al 2030. Es de esta manera, como se crean los Objetivos de Desarrollo Sostenible (ODS), una nueva ruta "que representa una oportunidad para incorporar las lecciones aprendidas en el proceso anterior" (Naciones Unidas).

De esta manera, será necesario analizar, por un lado, la implementación de los ODS en el ordenamiento jurídico con algunas referencias a la experiencia comparada, y por otro, la garantía para la disponibilidad de agua y su gestión sostenible y el saneamiento para todos. Es a partir de estos enfoques como se pretende identificar el alcance e implementación del "agua limpia y saneamiento" como Objetivo de Desarrollo Sostenible.

\subsection{Los Objetivos de Desarrollo Sostenible (ODS) y su implementación en el ordenamiento jurídico colombiano. Consideraciones generales}

Los Objetivos de Desarrollo Sostenible (en adelante ODS) se desarrollaron a partir de la Conferencia de las Naciones Unidas sobre el Desarrollo Sostenible celebrada en Río de Janeiro en el año 2012. De acuerdo con el Programa de las Naciones para el Desarrollo (en adelante PNUD), tenían como propósito, "crear un conjunto de objetivos mundiales relacionados con los desafíos ambientales, políticos y económicos con que se enfrentaría nuestro mundo" (PNUDa).

Por otro lado, producto de la herencia de los Objetivos de Desarrollo del Milenio (en adelante ODM) proyectados a inicios del presente siglo, los ODS retomaron la pretensión de sumar esfuerzos concertados de comunidades, autoridades locales, nacionales y de cooperación internacional para combatir la pobreza en sus múltiples dimensiones, lograr la enseñanza primaria universal, promover la igualdad de género y la autonomía o empoderamiento de la mujer, reducir la mortalidad infantil, mejorar la salud materna, combatir enfermedades, fomentar una asociación 
mundial para el desarrollo y garantizar la sostenibilidad del medio ambiente (PNUD, 2015, p. 7 13).

En desarrollo de estos propósitos, los ODS se enfocaron en diecisiete puntos fundamentales que complementaron los ODM a partir de una visión general de las necesidades sociales y la vanguardia de las mismas. En tal sentido, se estructuraron como un llamado universal a la adopción de medidas que "incluyen nuevas esferas como el cambio climático, la desigualdad económica, la innovación, el consumo sostenible y la paz y la justicia, entre otras prioridades" (PNUD).

No será objeto del presente escrito analizar a profundidad cada uno de los ODS, sin embargo, se hará mención de ellos con particular énfasis en el objetivo número seis, que consiste en garantizar la disponibilidad de agua y su gestión sostenible y el saneamiento para todos (PNUD).

En primer lugar, atendiendo a que los ODS

(...) deben estar orientados a la acción, ser concisos y fáciles de comunicar, limitados en su número y ambiciosos, tener un carácter global y ser universalmente aplicables a todos los países, teniendo en cuenta las diferentes realidades, capacidades y niveles de desarrollo nacionales y respetando las políticas y prioridades nacionales (Naciones Unidas, 2012, p. $51)$.

Se fijaron como ODS, las siguientes proyecciones, que para efectos metodológicos se agruparán en tres categorías, con el ánimo de brindar un orden en su entendimiento. Sin embargo, esto no significa que las categorías sean independientes, por el contrario, es necesario la concatenación y articulación de ellas y sus componentes, para lograr lo descrito en párrafos precedentes. Además, es necesario precisar que la agrupación no es excluyente ni exclusiva, por tal razón, un objetivo puede pertenecer a cualquiera de los tres grupos propuestos. En este sentido, se agruparán los ODS en objetivos para alcanzar el bienestar social y el desarrollo individual, objetivos para un entorno ambientalmente sostenible y objetivos para alcanzar el progreso colectivo e institucional.

Dentro de los objetivos para alcanzar el bienestar social y el desarrollo individual, se encuentra la búsqueda para ponerle fin a la pobreza y el hambre en todas sus formas, logrando un esquema de seguridad alimentaria y una mejora de la nutrición y la promoción de la agricultura sostenible. Estos objetivos se complementan con la garantía de una vida sana, promoviendo el bienestar para todas las edades y asegurando la disponibilidad de agua y su gestión sostenible, así como el saneamiento para todos. De igual modo, la garantía de una educación de calidad, equitativa e inclusiva que contribuya a lograr la igualdad de género (PNUD).

Por su parte, los objetivos para un entorno ambientalmente sostenible buscan en términos del PNUD, lograr que las ciudades y los asentamientos humanos sean inclusivos, seguros y sostenibles, que se garanticen las modalidades de consumo y producción, que se adopten medidas urgentes para combatir el cambio climático y sus efectos, conservar y utilizar de modo sostenible los recurso marinos, gestionar la sostenibilidad de los bosques a través de programas que promuevan el cuidado de la tierra y que se garantice un acceso adecuado a una energía asequible (PNUD).

Los objetivos para alcanzar el progreso colectivo e institucional abarcan la promoción del crecimiento económico sostenido, inclusivo y sostenible, garantizar empleo pleno y trabajo decente para todos, la promoción de la industria, la innovación y la infraestructura, la reducción de la brecha de desigualdad entre los países y la promoción de sociedades justas pacíficas e inclusivas (PNUD). Con relación a su implementación, en el ordenamiento jurídico colombiano a través del Consejo Nacional de Política Económica y Social, desarrolló una estrategia para la implementación de los ODS a partir de un diagnóstico que comprende balance, retos y deficiencias para así definir la política y los lineamientos en su implementación (CONPES, 2018, p.3). 
En términos generales, el CONPES deja de presente que en Colombia los ODS se incorporan a "las agendas que actualmente adelanta el país en materia de desarrollo, así como un marco que permite alinear de manera coherente acciones tanto públicas como privadas alrededor de un objetivo común" (CONPES, 2018, p.8).

Atendiendo al cumplimiento de esas agendas, el DNP a través de la Dirección de Seguimiento y Evaluación de Políticas Públicas, identificó que en los Planes de Desarrollo Territorial (en adelante PDT), la inclusión de los ODS en una proyección desde el 2016 hasta el 2019, arrojó que de los 32 departamentos, "en 24 PDT se dio en forma general; en otros 24 se presento una incorporación media; mientras que, en 15 de ellos se evidenció una incorporación alta" (CONPES, 2018, p.9). Los criterios utilizados para analizar esta inclusión se basaron en la mención de los ODS en su plan y la estructuración de ejes, metas y programas a partir de los mismos.

Igualmente, en términos de ejecución, el CONPES señala que "se alcanzó un promedio de cumplimiento de $86,8 \%$ para los ocho objetivos establecidos en la Declaración del Milenio" (CONPES, 2018, p.17). Sin embargo, deja claro que "existen dificultades de articulación con otros actores, particularmente con organizaciones no gubernamentales y la sociedad civil”, así como una "ausencia de una estrategia de los ODM a nivel territorial" (CONPES, 2018, p.23).

Muestra de esta dificultad, se traduce en una ausencia de un adecuado esquema de seguimiento a la implementación de los objetivos a nivel nacional y territorial, que el mismo sea accesible a la ciudadanía a través de ejercicios de rendición de cuentas. Asimismo, coloca de presente una limitada articulación en el "involucramiento de la sociedad civil y el sector privado en la formulación, implementación y monitoreo de las acciones emprendidas por el Gobierno Nacional" (CONPES, 2018, p. 28).

A pesar de lo anterior el CONPES puede lograr consolidarse como una herramienta, "punto de referencia en la formulación de lineamientos de política en temas que están bajo el liderazgo del Gobierno Nacional", que oriente los planes de trabajo a través de una Secretaría Técnica para el diseño de agendas fijas, principalmente, hacia el año 2030 (CONPES, 2018, p. 28). No obstante, es importante que la implementación se logre a través de la descentralización territorial, pues a través de un efectivo ejercicio de la autonomía en los territorios, se logra focalizar la necesidad y así proyectar la incorporación del objetivo correspondiente. Muestra de lo anterior, corresponde a su articulación a través de los PDT.

En el mismo sentido, el DNP destacó que "el compromiso de Colombia hacia el cumplimiento de los ODS se evidencia en la incorporación de 92 de las 169 metas" de la Agenda global de desarrollo al año 2030 en el Plan Nacional de Desarrollo 2014-2018 (DNP).

Desde el punto de vista institucional, se creó la Comisión Interinstitucional de Alto Nivel ODS, la cual tiene por objeto el "alistamiento y la efectiva implementación de los ODS a través de políticas públicas, planes, acciones y programas, con planificación prospectiva, y el monitoreo, seguimiento y evaluación de estos objetivos, con sus respectivas metas" (Decreto 280, 2015, art. 1,2).

Las funciones que tiene a cargo la comisión, comprende desde la definición de los mecanismos, metodologías y procesos necesarios para el alistamiento en la implementación de los objetivos, la identificación de necesidades relacionadas con el cumplimiento de los mismos, hasta la estructuración de sistemas de vinculación de capital privado, bien sea a través de esquemas de asociación público-privadas, para promover espacios, mecanismos de cooperación y fortalecimiento en la capacidad de las entidades, entre otros (Decreto 280, 2015, art. 4).

Desde una experiencia comparada, la institucionalidad para la implementación de los ODS no es exclusiva en Colombia. A modo de ejemplo, se resalta la Comisión Interinstitucional de Alto Nivel Político para el Desarrollo Sostenible de República Dominicana, cuyo mandato consiste en "trazar 
la ruta para una efectiva implementación de la Agenda de Desarrollo Sostenible" (Decreto 23, 2016, art. 1), con unas funciones similares a la de Colombia.

Para el caso brasileño, se creó la Comissão Nacional para os Objetivos de Desenvolvimento Sustentável do Brasil (CNODS), una dependencia del Gobierno Federal de carácter consultivo, encargada de la elaboración de las estrategias, instrumentos, acciones y programas de implementación de los ODS, asimismo, acompañar su implementación y promover la articulación de los organismos y las entidades públicas (Decreto 8892, 2016, art. 1-2).

La fijación de políticas y herramientas para la implementación de los ODS en Colombia, así como la necesidad de adecuar la institucionalidad al cumplimiento de la Agenda 2030, consta de múltiples particularidades atendiendo a cada objetivo. Sin embargo, para delimitar el objeto del presente escrito, se dará énfasis en la garantía para la disponibilidad de agua y su gestión sostenible y el saneamiento para todos.

\subsection{Garantía para la disponibilidad de agua y su gestión sostenible y el saneamiento para todos: Un objetivo en construcción}

El reconocimiento del agua como elemento básico del desarrollo sostenible y la reafirmación de los compromisos contraídos en el Plan de Aplicación de las Decisiones de Johannesburgo sobre Desarrollo Sostenible, concretamente, la prioridad frente al abastecimiento de agua y el saneamiento, así como el suministro de agua limpia y potable (Naciones Unidas, 2002, p. 11), se complementan con el objetivo de la Declaración del Milenio de reducir a la mitad, para el año 2015, el porcentaje de personas sin acceso sostenible al agua potable y a servicios básicos de saneamiento (Comisión Económica para América Latina y el Caribe (en adelante (CPAL), 2008). Atendiendo al interés que engloba la prioridad en el abastecimiento de agua limpia y potable a la población, la Organización de las Naciones Unidas para la Educación, la Ciencia y la Cultura (en adelante UNESCO), coloca de presente que para el 2016,

El acceso al agua apta para el consumo y el acceso al saneamiento básico son derechos humanos, reconocidos como tales por las Naciones Unidas. Sin embargo, actualmente ambos están lejos de ejercerse como derechos efectivos para muchos millones de personas en todo el mundo. Actualmente, al menos 663 millones de personas no tienen acceso al agua potable, 2.400 millones no disponen de sistemas de saneamiento adecuados (UNESCO, 2016, p.12-13).

Para el caso de América Latina, la mayoría de los países carecen de un adecuado marco legal e institucional, una suficiencia en la cobertura y la calidad del servicio, falta de eficiencia y capacidad operativa, una desproporción en los valores tarifarios y en los subsidios, hasta un problema relacionado con la información, la transparencia y la rendición de cuentas en las actuaciones públicas que incorporan el recurso hídrico (Banco Interamericano de Desarrollo (en adelante BID) \& Banco de Desarrollo de América Latina (en adelante CAF), 2015, p. 39).

Frente a esta problemática alarmante, la ONU-Agua está desarrollando un trabajo exhaustivo para proponer un sistema de medición de los avances en la consecución de las metas de este objetivo, para ello, cuenta con diferentes instituciones o programas, algunos de ellos existentes otros en construcción, "entre los que ha distribuido la responsabilidad del establecimiento de los sistemas de seguimiento" (UNESCO, 2016, p.19).

Dentro de los resultados concretos que han logrado estos programas e instituciones se encuentran, el acceso al agua potable para 1.300 millones de personas de países en desarrollo, atendiendo a la Conferencia de las Naciones Unidas sobre el Agua en 1977 de Mar de Plata, Argentina, el Decenio 
Internacional del Agua Potable y del Saneamiento Ambiental (1981-1990), etc. Del mismo modo, una contribución proporcional y adicional después del Decenio Internacional de Acción "Agua para la Vida" 2005-2015 (ONU).

La más reciente puesta en marcha del "Decenio Internacional para la Acción, Agua para el Desarrollo Sostenible", comenzó el 22 de marzo de 2018 y terminará en el 2028. A través de este programa, la Asamblea General de la $\mathrm{ONU}^{6}$, reitera y reconoce una realización progresiva del acceso universal a través de, la cooperación y asistencia internacional, la armonización de las metas y los indicadores con los derechos humanos, los enfoques intersectoriales y la participación y empoderamiento de la sociedad civil (ONU, 2010).

De esta manera, los países miembros asumen una serie de obligaciones de derechos humanos relacionadas con el acceso al agua potable y el saneamiento. Para el caso colombiano, la Política Nacional para la Gestión Integral del Recurso Hídrico (en adelante, PNGIRH), parte de un diagnóstico sobre el estado, la gestión y los aspectos económicos y financieros del recurso (Ministerio de Ambiente, Vivienda y Desarrollo Rural, 2010).

Así, en primer lugar, se identifica el marco institucional liderado por el Ministerio de Ambiente, Vivienda y Desarrollo Sostenible y su correspondiente sector administrativo ${ }^{7}$, el cual, está compuesto por autoridades ambientales del orden nacional y territorial, encargadas de "la administración del medio ambiente y de los recursos naturales renovables, incluida el agua", las cuales "ejecutan políticas, planes, programas y proyectos específicos para manejar, proteger, regular y controlar la disponibilidad, calidad y uso del recurso hídrico (Ministerio de Ambiente, Vivienda y Desarrollo Rural, 2010, p. 12).

El desarrollo de la política obedece a diferentes antecedentes, cuya construcción ha sido gradual. Estos antecedentes se relacionan con objetivos específicos, que para el asunto que interesa el presente escrito, resulta relevante destacar, el "estudio y definición del desarrollo de infraestructura tendiente a almacenamiento artificial de agua, que permita regular los excesos en períodos húmedos y garantizar el suministro y distribución en períodos de déficit" (Ministerio de Ambiente, Vivienda y Desarrollo Rural, 2010, p. 16).

Asimismo, frente al desperdicio y contaminación del recurso, se propuso la adopción de "tecnologías y crear hábitos de consumo", así como "orientar un uso eficiente del agua a través de la formación de una conciencia de uso racional" (Ministerio de Ambiente, Vivienda y Desarrollo Rural, 2010, p. 15). Adicionalmente, para consolidar la política, frente a estos objetivos y problemáticas se han elaborado una serie de "lineamientos para la construcción colectiva de una cultura del agua", los cuales, involucran estrategias para la satisfacción de las necesidades fundamentales relacionadas con el agua. A pesar de lo importante que resulta estos mecanismos, la articulación de instituciones y los mecanismos para alcanzar los propósitos, aún resultan insuficientes y complejos en su implementación.

Por su parte, la política no sólo identifica el componente institucional para la efectividad de la gestión. El factor normativo resulta relevante para precisar el alcance regulatorio en la garantía del agua potable y saneamiento básico. En este sentido, recientemente el Ministerio de Vivienda, Ciudad y Territorio, reformó y expidió el nuevo "Reglamento Técnico para el Sector de Agua

\footnotetext{
${ }^{6}$ Para el particular puede verse la Resolución aprobada por la Asamblea General del 21 de diciembre de 2016, el documento sobre las obligaciones de derechos humanos relacionadas con el acceso al agua potable y el saneamiento del 6 de agosto de 2010, la Nota de la Secretaría de las naciones Unidas para el agua, la paz y la seguridad: la cooperación en la gestión de las aguas transfronterizas, etc.

7 En términos del art. 42 de la Ley 489 de 1998, "el sector administrativo está integrado por el ministerio o departamento administrativo, las superintendencias y demás entidades que la ley o el Gobierno Nacional definan como adscritas o vinculadas a aquéllos según correspondiere a cada área".
} 
Potable y Saneamiento Básico (RAS)", a través del cual se pretende, entre otras cosas, garantizar la calidad de la prestación de los servicios, lograr la atención prioritaria de las necesidades básicas insatisfechas en materia de agua potable y saneamiento básico, buscar la ampliación permanente de las coberturas de los servicios y garantizar la prestación continua e ininterrumpida de los servicios (Resolución 0330, 2017, art. 3).

El RAS contempla la planeación de proyectos de infraestructura articulando planes o esquemas de ordenamiento territorial, los planes ambientales, regionales y sectoriales (Resolución 330, 2017, art. 5,6). Estos proyectos, están diseñados a partir de estudios previos y etapas para identificar el alcance de la necesidad para la priorización de los proyectos (Resolución 330, 2017, art. 12). Seguidamente, da contenido al "diseño de ingeniería detallado previo al inicio de la construcción" (Resolución 330, 2017, art. 20). Finalmente, desarrolla asuntos relativos a la operación, mantenimiento, interventoría, sistemas de abastecimiento y captación del recurso hídrico.

En efecto, el avance y actualización de carácter técnico fortalece la construcción de la seguridad hídrica en el país y la adecuada implementación de los Objetivos de Desarrollo Sostenible. En consonancia con este propósito, a través del Plan Director de Agua y Saneamiento Básico 20182030 del Ministerio de Vivienda (2018b, p. 33), se reitera que el "nexo existente entre el agua y los demás sectores determinan que el cumplimiento del ODS 6 sea un requerimiento fundamental e indispensable para alcanzar satisfactoria y conjuntamente los demás ODS”.

Por tal razón, a través de la expedición del CONPES 3918, el Plan Director de Agua y Saneamiento Básico, así como del desarrollo de la hoja de ruta para cada una de las metas establecidas, concretamente, con relación al agua potable y el saneamiento básico, se espera lograr el acceso universal y equitativo al agua potable a un precio asequible para todos, mejorar la calidad de agua, y lograr el acceso a servicios de saneamiento e higiene adecuados y equitativos para todos (Ministerio de Vivienda, 2018, p. 34-35).

Desde la experiencia comparada, la implementación para la garantía del agua potable y el saneamiento básico también representa un proceso gradual. En Brasil, el proyecto "objetivo de desenvolvimento sustentável 6- Água e saneamento: Estudos e proposição de medidas para implementação e monitoramento" ${ }^{\circ}$, desarrolla una metodología a partir de tres pilares que agrupan los contenidos para la investigación y las acciones previstas en materia de agua potable.

Entre los pilares se destaca, el análisis de los elementos de éxito a nivel comparado en la gestión del agua, la formulación de proposiciones de modernización de las medidas estatales, y la elaboración de una propuesta de implementación, a partir de componentes político-institucionales, financieros y técnico operacionales (Instituto de Pesquisa Econõmica Aplicada -ipea, 2018, p. 2).

Tomando en consideración lo anterior, los productos del proyecto se han sustentado en propuestas técnicas y de divulgación académica. Lo que permite inferir el carácter consultivo del proyecto para las entidades del orden federal, el cual, se enfoca en el diseño de una estrategia de monitoreo y de mecanismos de gestión a los programas y políticas públicas que contribuyan con el alcance del objetivo.

Para el caso de Australia, el Departamento de Asuntos Exteriores y de Comercio publicó el "Report on the Implementation of the Sustainable Developement Goals 2018”. A través de este informe, se resaltan los avances y retos de la Iniciativa Nacional del Agua promovida en el año 2004. En este sentido, las acciones del acuerdo se han implementado a partir de una agenda concreta, con un calendario establecido dentro de un territorio específico. Del mismo modo, parten de un ideal

\footnotetext{
${ }^{8}$ El proyecto ha sido desarrollado por el Instituto de Pesquisa Econõmica Aplicada (ipea) en conjunto con la Agência Nacional de Aguas (ANA), o Ministério do Meio Ambiente y la Comissão Nacional para os Objetivos de Desenvolvimento Sustentável.
} 
cooperativo entre los Estados y territorios que comparten agua, para asegurar la correcta ejecución de acciones judiciales y administrativas que se relacionen con el recurso hídrico (Department of Agriculture and Water Resources, 2004, No. 2-3).

La Iniciativa identifica y asigna competencias específicas a cada una de las entidades o dependencias relacionadas con la gestión del recurso hídrico. Asimismo, expone un escenario de auditoría a satisfacción del gobierno central (Department of Agriculture and Water Resources, 2004, p. 10).

Bajo esta delegación, desconcentración y descentralización de las funciones administrativas, se estructura un proyecto cuyo eje central lo constituye la atribución de reponsabilidades para trabajar hacia objetivos comunes. La clave de la iniciativa es la integración. Por tal razón, evaluando los resultados de su implementación, se propone compartir su experiencia para fortalecer las economías y reducir la pobreza en el mundo (Department of Foreign Affairs and Trade, 2018, p. 48-51).

Alcanzar el cumplimiento de las metas proyectadas a 2030 es un objetivo en construcción. De ahí que, se hace indispensable una adecuada planeación y regulación de las políticas, planes y proyectos relacionados con el abastecimiento y la potabilidad del recurso hídrico.

\section{LA CALIDAD REGULATORIA Y EL SUMINISTRO DE AGUA POTABLE Y SANEAMIENTO}

Según el Plan Director de Agua y Saneamiento Básico 2018-2030 para Colombia (2018b, p. 8), “el sector de agua potable y saneamiento básico adolece en la actualidad de un documento de política pública con una visión estratégica" de cara al cumplimiento de los ODS, los compromisos adquiridos en la Conferencia de las Partes (COP21) y la Convención Marco de las Naciones Unidas sobre el Cambio Climático (CMNUCC).

A pesar de que el CONPES 3918 responde a una estrategia para la implementación de los ODS, su contenido, como se indicó, constituye solo el "punto de referencia" para el cumplimiento de estos objetivos. Por tal razón, la apreciación y esfuerzo del Gobierno Central por presentar una propuesta para atender a la prioridad del sector de agua potable y saneamiento, es fundamental en la consecución de acciones concretas de corto, mediano y largo plazo (Ministerio de Vivienda, 2018, p. 9).

Al mismo tiempo, el diseño, implementación y ejecución de cualquier propuesta encaminada a asegurar el objetivo, como se colocó de presente a lo largo de este escrito, requiere de un análisis desde el derecho, pues lleva consigo la satisfacción y garantía de varios derechos fundamentales (Corte Constitucional, C-546, 2009).

Son diferentes las apreciaciones relacionadas con la necesidad de ejecutar propuestas o proyectos para la garantía del agua potable y el saneamiento básico en los países en desarrollo y subdesarrollados. De modo que, incorporar criterios para analizar su inclusión y seguimiento, constituye una herramienta que se puede desarrollar a partir de la inclusión de prácticas de mejora regulatoria.

En este contexto, la mejora regulatoria "está estrechamente vinculada a los principios constitucionales y diversas legislaciones que determinan la manera en que la administración pública se ocupa de las leyes y las regulaciones, desde su diseño y concepción hasta su implementación y revisión" (OCDE, 2014, p. 19-23). Con lo anterior, es necesario precisar que estas prácticas no son exclusivas del sector ejecutivo, sino que su aplicación puede extenderse a las otras ramas del poder público. 
Para impulsar la mejora regulatoria en la garantía del agua potable y de saneamiento, se hace necesario la aplicación de diferentes prácticas para alcanzar la calidad en el servicio. Entre ellas se encuentran, el diseño de una agenda regulatoria, la aplicación de una evaluación de impacto ex post y ex ante, la abogacía de la competencia, etc. Algunas de ellas serán desarrolladas en el presente escrito.

\subsection{La agenda regulatoria en el suministro de agua potable y saneamiento}

La agenda regulatoria, en términos generales, se define como la programación de objetivos, eventos y circunstancias a los que debe orientarse la política regulatoria de un país. Esta agenda se estructura a partir de una propuesta, proyecto o sector específico, la cual debe atander a criterios generales establecidos para lograr la efectividad en su implementación.

Dentro de los criterios generales se encuentran, la identificación de unos antecedentes que justifiquen la necesidad de implementar una agenda regulatoria para el sector, una metodología para su estructuración, el diseño de los proyectos regulatorios y la agenda regulatoria indicativa con una proyección concreta y real (CRA, 2018) (Decreto, 1077, 2015, art. 2.3.6.3.2.6).

En Colombia, el Decreto 2696 de 2004, dispone que "Las Comisiones de Regulación tendrán la obligación de definir un plan estratégico para períodos mínimos de cinco (5) años y una agenda regulatoria anual de carácter indicativo" (Decreto, 2696, 2004, art. 6). En concordancia con lo anterior, la definición del plan corresponde a una política e iniciativa sectorial, limitada en el tiempo, y cuya planeación debe atender a criterios sociales, económicos y culturales.

Para el sector de agua potable y saneamiento básico, la CRA, atendiendo a la implementación por parte del Gobierno Nacional de acuerdos y compromisos derivados del ingreso de Colombia a la Organización para la Cooperación y el Desarrollo Económico (OCDE), identifica como antecedentes, los problemas y necesidades del sector y de los usuarios del servicio público domiciliario de acueducto, alcantarillado y aseo, asi como, los desarrollos normativos que sobre el asunto se han expedido (CRA, 2018, p.2).

Asimismo, desde el punto de vista metodológico, la propuesta de agenda regulatoria indicativa del sector, es desarrollada con los principios de análisis de impacto normativo, instrumento sobre el cual se dará un desarrollo posterior. Sin embargo, cabe advertir que la estructura parte de la definición de objetivos, alternativas, evaluación, selección y consulta a grupos de interés para determinar la efectividad en la aplicación del progama (CRA, 2018, p.4).

Por otro lado, desde la agenda regulatoria indicativa para el 2018 y la proyección 2019, el diseño de proyectos se centra en una metodología para clasificar las personas prestadoras de los servicios públicos domiciliaros de acueducto y alcantarillado con un nivel de riesgo, la regulación frente a tarifas por actividad del servicio y tratamiento de vertimientos, la medición del consumo para usuarios del servicio público, que cuenten con fuentes alternas de abastecimiento de agua potable (CRA, 2018, p.3-4).

En efecto, la ejecución y cumplimiento de la agenda regulatoria tiene una proyección paulatina, cuya incorporación no solo depende de una voluntad administrativa, sino también de un adecuada infraestructura y acceso para garantizar el suministro de agua potable y saneamiento a las poblaciones más apartadas.

Cuando se hace referencia a que la planeación debe atender a múltiples factores, el instrumento a través del cual se hace manifiesto ese propósito, ha sido instrumentalizado en un documento sectorial sujeto al concepto ciudadano (DNP). Sin embargo, es necesario avanzar en el diseño de propuestas concretas y viables, pues de este manera, todos los instrumentos para la mejora regulatoria no se quedan en buenos e ideales propósitos. 


\subsection{El Análisis de Impacto Regulatorio para la formulación de una adecuada política de acueducto y agua potable.}

Además de una agenda regulatoria que atienda a una metodología y unos objetivos determinables, el Análisis de Impacto Regulatorio o Regulatory Impact Analysis (RIA) ${ }^{9}$, representa una herramienta empleada para el diseño e implementación de políticas públicas, pues es consecuente con la calidad en el ejercicio de la actividad administrativa, la eficiencia y efectividad en la prestación del servicio público y la ejecución de una economía competitiva que atienda al bienestar del consumidor (Department of the Taoiseach Government Buildings Dublin, 2009, p.2-3).

Una vez programados los objetivos, eventos y circunstancias para una política regulatoria determinada. El Análisis de Impacto Regulatorio se erige como un proceso de evaluación e identificación sistemática de los efectos esperados en las propuestas regulatorias, utilizando un método analítico y comparativo del costo/beneficio basado en los objetivos de la política regulatoria y de intervención para alcanzar estándares de calidad (Organisation for Economic Cooperation and Development- OECD, 2008, p. 3).

De esta manera, la CRA ha establecido para la ejecución de la agenda regulatoria del Servicio Público de Acueducto, alcantarillado y aseo, la correspondiente atención a los principios de la metodología de Análisis de Impacto Normativo (en adelante AIN) (CRA, 2018, p.2).

En atención a lo anterior, el CONPES 3816 de 2014 "Mejora Normativa: Análisis de Impacto" indica, que la herramienta empleada para el diseño, proceso, identificación y ejecución de las propuestas regulatorias, corresponde con una adecuada producción normativa, la cual "ocupa un espacio central en la implementación de políticas (...), siendo el medio a través del cual se estructuran los instrumentos jurídicos que materializarán gran parte de las decisiones del Estado, y cuyo impacto es tan importante como el de la política fiscal y monetaria (CONPES, 2014, p. 8).

Así pues, el análisis de impacto se hace efectivo tras la decisión de intervenir a través de la regulación. Sin embargo, la decisión de intervenir o no, es consecuencia de un proceso que inicia con la identificación de un problema, etapa en la cual los antecedentes juegan un papel fundamental, entiéndase esto a través de un ejemplo concreto:

Chocó es uno de los departamentos más abandonados del país (...) Noanamá, un caserío en el Medio San Juan chocoano, cuenta con aproximadamente 450 habitantes que viven en 200 casas de madera y techo de cinc. Estos colombianos no tienen acceso al agua potable. (Revista Semana, 2017)

En el caso anterior, es manifiesta una situación que afecta negativamente a determinado grupo social, la causa quizá corresponde con un problema de equidad y una ausencia del Estado en el territorio. De acuerdo con esto, se identifica el problema: la falta de acceso al agua potable. Ahora bien, identificado el problema, es procedente la evaluación y diagnóstico del mismo, en esta fase, se reconocen los actores que están involucrados, el territorio sobre el cual se hace necesario intervenir, y uno de los elementos más importantes, establecer si ya existen mecanismos jurídicos a través de los cuales pueda hacerse efectiva la garantía en el suministro y acceso de agua potable y saneamiento.

\footnotetext{
${ }^{9}$ El RIA tiene una denominación distinta dependiendo la adopción de los países, por ejemplo en Colombia corresponde con el Análisis de Impacto Normativo (AIN), en México, Manifestación de Impacto Regulatorio, para Brasil, Análise de Impacto Regulatório - AIR, y el tradicional, Regulatory Impact Anlysis (RIA) en el Reino Unido.
} 
Finalmente, con el diagnóstico acompañado de un análisis causal que nutren el problema, se hace necesario tomar la decisión de intervenir o no y cual es el impacto que genera dicha intervención. Es ahí donde toma protagonismo el diseño y la implementación de una agenda regulatoria, que a nuestro juicio, debe ser de ejecución descentralizada territorialmente, pues permite tener un mayor control sobre la necesidad de formular objetivos claros, ejecutables y directamente relacionados con la problemática existente.

Con lo anterior, es manifiesto que la aplicación del Análisis de Impacto Normativo o Regulatorio, permite mejorar la calidad de las decisiones regulatorias, pues proporciona herramientas para el análisis y adecuación de las propuestas, en últimas, introduce un marco sistemático basado en la evidencia para el proceso de desarrollo de políticas (Australia Government- Productivity Commission, 2012, p.31).

A pesar de que estos mecanismos han sido diseñados para la toma de decisiones en sede administrativa, lo cierto es, que es necesaria su aplicación tanto por los jueces como por los legisladores y de alguna u otra manera, todo aquel que tenga la facultad de tomar decisiones en el plano público. Es así, como se implementa una metodología que cambia y organiza la tradición del ejercicio público.

\subsection{La abogacía de la competencia y la evaluación de impacto ex ante en el Servicio Público de Acueducto y Agua Potable}

La abogacía de la competencia comprende un conjunto de actividades realizadas por la autoridad administrativa, para la promoción de un entrono competitivo a nivel económico, mediante una interacción con otras entidades gubernamentales y el incremento de la conciencia pública sobre los beneficios de la competencia (De la Calle, 2012). Esto corresponde con la finalidad intervencionista del Estado en los servicios públicos, concretamente con la libertad de competencia y no utilización abusiva de la posición dominante, la obtención de economías de escalas comprobables, la atención prioritaria a las necesidades básicas insatisfechas en materia de agua potable y saneamiento básico, etc. (ley 142, 1994, art. 2).

Por lo que se refiere a la estructura institucional del sector, a parte de lo ya desarrollado en la primera parte del presente escrito, el DNP ha diseñado un esquema sobre el cual se identifican las entidades estrechamente relacionadas con la prestación del servicio. El esquema comprende entidades que pertenecen a diferentes sectores administrativos, entre ellas, el Ministerio de Vivienda, Ciudad y Territorio, el DNP, el Ministerio de Salud y Protección Social, la CRA, la SSPD y el Ministerio de Hacienda Crédito Público, así como el Ministerio de Ambiente y Desarrollo Sostenible.

Asimismo, no solo desde el sector central se estructura la actuación administrativa. Las Autoridades ambientales Regionales, los Departamentos, Municipios y Empresas de Servicios Públicos tienen un papel fundamental en la ejecución de planes y proyectos del sector. Vale la pena destacar la interacción entre estas entidades para cumplir con los objetivos trazados por el sector. Sin embargo, genera duda los canales de comunicación que existe entre estas dependencias, por lo cual, se hace necesaria la articulación de un proyecto concreto que organice las competencias y funciones para generar seguridad en la estructura institucional para la garantía del servicio.

Del mismo modo, es necesario resaltar que el esquema institucional para la garantía del servicio público de agua potable y saneamiento básico atiende a los propósitos de la abogacía de la competencia, pue involucra dependencias que atienden a la sostenibilidad fiscal, pero, por otro lado, las que preservan la garantía de los recursos naturales y su regulación. Esto por supuesto, genera un escenario competitivo. 
Por otra parte, la evaluación de impacto ex ante, es una herramienta de mejora regulatoria que se articula con la abogacía de la competencia. Pues a través de este mecanismo, las entidades promotoras de normas y proyectos encaminados al buen desarrollo del servicio, deben contar en su experiencia, con la facultad de solicitar a las entidades directamente involucradas con determinado proyecto, su concepto previo para así generar coherencia en la atribución de competencias y no un sin número de facultades con imposibilidad ejecutiva, pues en su mayoría, a pesar de tener la voluntad, no hay una infraestructura para lograr dicho cometido.

Usualmente, la evaluación ex ante al ejercicio normativo, se ha desarrollado con base en la incidencia sobre la libre competencia en los mercados (Ley 1340, 2009, art. 7). Sin embargo, la pauta metodológica de esta herramienta indica de manera general, la correspondencia con un mecanismo de gestión que coloca al operador público en un escenario hipotético a través del cual identifica un diagnóstico con base en lo ejecutado y desarrollado, para así determinar a través de diferentes enfoques, cualitativos y cuantitativos, si determinado proyecto o propuesta es viable en términos de ejecución y concreción de resultados.

Ahora bien, es importante tener de presente, que usualmente el concepto rendido por las entidades en el ejercicio de interacción o proposición no es vinculante. A nuestro juicio, esta consideración es infortunada. Pues en cierta medida, si todo proyecto de acto administrativo o ley atendiera las apreciaciones técnicas, jurídicas o políticas de organismos especializados en determinado sector, el escenario regulatorio contaría con mayor seguridad jurídica.

\subsection{Evaluación de impacto ex post y su necesidad para el Servicio Público de Acueducto y Agua Potable}

En el ciclo regulatorio, la evaluación de impacto ex post, pretende determinar la eficiencia y eficacia de la implementación y "en qué medida los impactos esperados o no esperados de la intervención regulatoria se atendieron adecuadamente al concebir el instrumento" (OCDE, 2012, p. 2). Esta evaluación corresponde con el último eslabón del análisis e implementación de instrumentos que atienden a la calidad o mejora regulatoria.

En otras palabras, identificada una problemática, fijados unos objetivos claros para su superación, estructurada una agenda concreta y limitada para el desarrollo de estos objetivos, revisadas las competencias y atendiendo a conceptos institucionales para una correspondiente asignación de funciones. La ejecución de un proyecto o política lleva consigo unos resultados que corresponden con un análisis y desafíos para futuras políticas. Así actúa la evaluación de impacto ex ante, como una herramienta que permite a quienes desempeñan funciones públicas, identificar el éxito o necesidad con la ejecución de una política determinada.

Desde un punto de vista comparado, uno de los países en implementar con éxito la evaluación ex post fue Australia. A través de la Oficina de Mejores Prácticas Regulatorias, se hace un seguimiento continuo a los procesos del sector infraestructura (electricidad, agua, gas, y telecomunicaciones) utilizando indicadores y evaluaciones de resultados que determinan la calidad del servicio, las tarifas y la actuación de las empresas de cada uno de los sectores. (Fundación para la Educación Superior y el Desarrollo (Fedesarrollo), 2012, p. 171). Sin embargo, la aplicación correcta de este instrumento sólo ha sido implementado en este país, los demás, han sido solo intentos malogrados. El reto para Colombia y la mayoría de los países de América Latina consiste en diseñar un mecanismo institucional, cuya elaboración requiere principalmente de un diseño interno de gestión para evaluar los resultados de la implementación de políticas relacionadas con el recurso hídrico, concretamente, el sector de agua potable y saneamiento, logrando así, replicar su éxito en otros 
intentos. Es quizá la experiencia, una de las herramientas más importantes para la implementación de los Objetivos de Desarrollo Sostenible.

\section{CONCLUSIONES}

La necesidad de abastecer los núcleos poblacionales urbanos y rurales para la satisfacción de las necesidades básicas, así como la urgencia por responder a la creciente demanda del recurso hídrico, son factores que referencian y contribuyen al adecuado ejercicio de la función administrativa, concretamente en la prestación de los servicios públicos.

En este sentido, la prestación adecuada, continua y universal del servicio público de Acueducto o Agua Potable, constituye una herramienta que logra alcanzar el propósito enunciado y brinda una respuesta frente a la problemática alrededor del recurso hídrico. Para alcanzar este cometido, el ejercicio de la función administrativa debe atender también a una serie de variables encaminadas a la satisfacción de los fines estatales, concretamente, el servicio a la comunidad y la garantía de los derechos constitucionales.

Esta finalidad se hace material estructurando y articulando diferentes elementos. Por un lado, la competencia de las entidades administrativas del sector central o descentralizado para asegurar la prestación eficiente de los servicios públicos. Donde pueden verse involucradas con una pluralidad de sujetos que actúan para la garantía del servicio bajo un régimen de libertad de entrada de acuerdo con los postulados constitucionales. A pesar de este escenario, la realidad muestra cierta clase de abusos en el ejercicio prestacional, que impide atender al escenario ideal en la prestación de los servicios públicos.

De otro lado, la ejecución prestacional debe atender aspectos técnicos que precisen el alcance de la distribución, conexión y medición, así como las actividades complementarias al servicio. En sintonía con la competencia y la técnica, la prestación del servicio tiene íntima relación con la satisfacción del interés de los múltiples partícipes en el ejercicio de la actividad, no solo el usuario y el prestador, sino también todos aquellos terceros que absoluta o relativamente se vean involucrados por la prestación del servicio.

Aún de la institucionalidad misma, pues en el ejercicio intervencionista, el Estado funge no solo como prestador, sino también como un ente de control y vigilancia para la adecuada prestación del servicio. Es por esto, por lo que se han dispuesto una serie de controles e instituciones sobre las cuales se delega, desconcentra o descentraliza la función administrativa.

Es pertinente destacar, que la prestación del servicio público no puede ser visto como una actividad del orden interno, es más, debe corresponder con los paradigmas y retos que plantee el orden internacional en materia de desarrollo y gobernanza. Muestra de ello, se relaciona con el vínculo que existe entre los servicios públicos y la satisfacción e implementación de los Objetivos de Desarrollo Sostenible.

Así pues, la garantía en el suministro de agua potable y saneamiento básico corresponde con un objetivo, cuyo marco de referencia debe inspirar la regulación del servicio público de acueducto y agua potable. En este sentido, son varios los esfuerzos emprendidos por Colombia y algunos países para alcanzar el bienestar social, el desarrollo sostenible, un entorno ambientalmente sostenible y el progreso colectivo e institucional.

Este propósito puede tomar mayor impulso a través de un ejercicio adecuado de las prácticas regulatorias. Lo cual, no se relaciona exclusivamente con la posibilidad de expedir normas o reglamentos que genéricamente analicen la garantía del agua potable y el saneamiento básico. Por el contrario, debe involucrar instrumentos encaminados a la búsqueda de la calidad prestacional de 
los servicios públicos. Que, entre otras cosas, permitan analizar el impacto de determinada disposición o conjunto de ellas, que se basen en una propuesta metodológica, tomando en consideración evaluaciones de impacto antes y después de generar una propuesta regulatoria.

Aunado a esto, el esfuerzo no puede ser exclusivo ni excluyente, éste debe atender a un paradigma en la visión de intervencionista del Estado, dando cabida y entendimiento a un pensamiento colaborativo, donde el Estado regula determinadas relaciones, pero interactúa para alcanzar el éxito y la calidad en ellas. Un ejercicio que no solo depende de la autoridad administrativa, sino también de todas las dependencias del Estado, más aún, de los jueces, quienes se han inclinado por la tendencia legisladora desde un punto de vista pasivo.

De acuerdo con lo anterior, una propuesta que involucre herramientas de mejora regulatoria permite focalizar y concretar el ejercicio prestacional del servicio público de acueducto y alcantarillado, haciéndolo más eficiente y garante en aras de alcanzar los propósitos de la Agenda 2030 y los Objetivos de Desarrollo Sostenible.

\section{BIBLIOGRAFÍA Y FUENTES DE INFORMACIÓN}

Amaya, O. (2018). Agua y Derecho Constitucional en Colombia. Volumen I. El derecho al agua y el servicio público de acueducto y alcantarillado desde la perspectiva de la Corte Constitucional. Bogotá D.C: Universidad Externado de Colombia.

Amaya, O. (2007). El régimen legal ambiental y su incidencia en la prestación de los servicios públicos de acueducto y alcantarillado. En Servicios Públicos y Medio Ambiente Tomo I. (pp. 113-142), Bogotá D.C: Universidad Externado de Colombia.

Amaya, O., Amaya, A. (2017). Aspectos ambientales de la prestación de los Servicios Públicos Domiciliarios. Bogotá D.C: Universidad Externado de Colombia.

Australia Government- Department of Foreign Affairs and Trade (2018). Report on the Implementation of the Sustainable Development Goals 2018. Recuperado de https://dfat.gov.au/aid/topics/development-issues/2030-agenda/Pages/sustainable-developmentgoals.aspx

Australia Government- Productivity Commission (2012). Regulatory Impact Analysis: Benchmarking, Canberra: Australia Government.

Banco Interamericano de Desarrollo (en adelante BID) \& Banco de Desarrollo de América Latina (en adelante CAF) (2015). El futuro de los Servicios de Agua y Saneamiento en América latina. Desafíos de los operadores de áreas urbanas de más de 300.000 habitantes. Recuperado de https://webimages.iadb.org/publications/spanish/document/El-futuro-de-los-servicios-de-agua-ysaneamiento-en-Am\%C3\%A9rica-Latina-Desaf\%C3\%ADos-de-los-operadores-de$\%$ C3\%A1reas-urbanas-de-m\%C3\%A1s-de-300000-habitantes.pdf

Comisión de Regulación de Agua Potable y Saneamiento Básico (2018). Propuesta Agenda Regulatoria Indicativa 2018. Recuperado de http://www.cra.gov.co/documents/AGENDAREGULATORIA-V6-2018-ModificadaNOVIEMBRE-2018.pdf 
Comisión de Regulación de Agua Potable y Saneamiento Básico (2018). Propuesta Agenda Regulatoria Indicativa 2019. Recuperado de http://www.cra.gov.co/documents/PropuestaAGENDA-REGULATORIA-INDICATIVA-2019-29oct.pdf

Comisión Económica para América Latina y el Caribe (2008). Lista oficial de los indicadores de los ODM. Recuperado de https://www.cepal.org/mdg/noticias/paginas/6/35556/officiallist2011_es.pdf

De la Calle, J. (2012). Abogacía de la competencia: La nueva tarea de la Superintendencia de Industria y Comercio. Con-texto-Revista de Derecho y Economía, 36, 59-78.

Departamento Nacional de Planeación. ¿Cuál ha sido el rol de Colombia en la definición de los ODS? Recuperado de https://sinergia.dnp.gov.co/Paginas/Internas/ODS/Por-qu\%C3\%A9.aspx

Departamento Nacional de planeación. Agua potable y saneamiento básico. Recuperado de https://colaboracion.dnp.gov.co/CDT/Vivienda\%20Agua\%20y\%20Desarrollo\%20Urbano/Agua/ Esquema\%20institucional\%202015.pdf

Departamento Nacional de Planeación. Mejora Regulatoria. Recuperado de https://www.dnp.gov.co/programas/Mejora\%20Regulatoria/Paginas/Quienes-somos.aspx

Department of the Taoiseach Government Buildings Dublin. (2009). Revised RIA Guidelines. How to conduct a Regulatory Impact Analysis. Dublin: Department of the Taoiseach

García, M.P. (2017). Régimen Jurídico de los Vertimientos en Colombia. Bogotá D.C: Universidad Externado de Colombia.

Federación para la Educación Superior y el Desarrollo - Fedesarrollo. (2012). Evaluación del marco regulatorio expedidio por la Comisión de Regulación de Comunicaciones entre 2009 y 2001. Informe final. Recuperado de https://www.crcom.gov.co/recursos_user/Documentos_CRC_2013/Actividades_Regulatorias/Eva luacion_Marco_CRC_Informe_Final_ago2013.pdf

Fernández, J. (2016). El servicio Público. En Fernández, J. (coord.). Grandes temas constitucionales. Derecho Administrativo. Ciudad de México: Secretaría de Gobernación, Secretaría de Cultura, INEHRM, UNAM-IIJ.

Instituto de Pesquisa Econõmica Aplicada - ipea (2018). Projeto "Objetivo de Desenvolvimento sustentável 6- Água e saneamento: Estudos e proposição de medidas para implementação e monitoramento. Recuperado de http://www.ipea.gov.br/portal/images/stories/PDFs/180205_sumario_do_plano_de_trabalho_OD S_9_jan.pdf

Liga de Consumidores de Bogotá. Preguntas y Respuestas Servicios Públicos Domiciliarios. Disponible en http://ligaconsumidoresbogota.org/soluciones-consumma/preguntas-y-respuestasde-servicios-publicos-domiciliarios/ 
Ministerio de Ambiente, Vivienda y Desarrollo Rural (2010). Política Nacional para la Gestión Integral del Recurso Hídrico. Recuperado de https://www.minambiente.gov.co/images/GestionIntegraldelRecursoHidrico/pdf/Presentaci\%C3 \%B3n_Pol\%C3\%ADtica_Nacional_Gesti\%C3\%B3n_/libro_pol_nal_rec_hidrico.pdf

Ministerio de Vivienda, Ciudad y Territorio (2018). Plan director agua y Saneamiento Básico. Visión Estratégica 2018-2030. Recuperado de http://www.minvivienda.gov.co/Documents/ViceministerioAgua/Plan\%20Director.pdf

OCDE (2012). La Evaluación de las Leyes en Chile. Resumen Ejecutivo. Paris: OCDE

OCDE (2014). Estudio de la OCDE sobre la política regulatoria en Colombia: Más allá de la simplificación administrativa. Paris: OCDE.

Organización de las Naciones Unidas (2002). Plan de Aplicación a las decisiones de la Cumbre Mundial Sobre Desarrollo Sostenible en Johannesburgo. Recuperado de http://www.un.org/spanish/esa/sustdev/pdf/WSSD_PlanImpl.pdf

Organización de las Naciones Unidas (2010). Obligaciones de derechos humanos relacionadas con el acceso al agua potable y el saneamiento. Nota del Secretario General (2010). Recuperado de https://undocs.org/es/A/65/254

Organización de las Naciones Unidas (2012). Documento final de la conferencia de las Naciones Unidas sobre el Desarrollo Sostenible Rio+20. Recuperado de https://rio20.un.org/sites/rio20.un.org/files/a-conf.216-1-1_spanish.pdf.pdf

Organización de las Naciones Unidas. Agua. Recuperado de http://www.un.org/es/sections/issues-depth/water/index.html

Organización de las Naciones Unidas. Objetivos de Desarrollo del Milenio. Recuperado de http://www.un.org/es/development/desa/millennium-development-goals.html

Organización de las Naciones Unidas (1977). Conferencia de las Naciones Unidas sobre el Agua en 1977 de Mar de Plata, Argentina. Recuperado de

https://www.who.int/water_sanitation_health/unconfwater.pdf Organización de las Naciones Unidas para la Educación, la Ciencia y la Cultura (UNESCO) (2016). Los derechos humanos al agua potable y al saneamiento en la Agenda 2030. Recuperado de http://www.unescoetxea.org/dokumentuak/dossier_agua_agenda2030.pdf

Organization for Economic Co-operation and Development - OECD., (2008). Introductory Handbook for undertaking Regulatory Impact Analysis (RIA). Recuperado de https://www.oecd.org/gov/regulatory-policy/44789472.pdf

Programa de las Naciones para el Desarrollo (PNUD). Objetivo 6: Agua limpia y saneamiento. Recuperado de http://www.undp.org/content/undp/es/home/sustainable-development-goals/goal6-clean-water-and-sanitation.html 
Programa de las Naciones Unidas para el Desarrollo (PNUD). ¿Qué son los Objetivos de Desarrollo Sostenible? Recuperado de http://www.undp.org/content/undp/es/home/sustainabledevelopment-goals/background.html

Programa de las Naciones Unidas para el Desarrollo (PNUD). (2015). Objetivos de Desarrollo del Milenio. Informe 2015. Recuperado de http://www.co.undp.org/content/dam/colombia/docs/ODM/undp-co-odsinformedoc-2015.pdf

Revista Semana (21 de noviembre de 2017). La exposición que busca aliviar la falta de agua potable en Chocó. Revista Semana. Recuperado de https://www.semana.com/cultura/articulo/nohay-agua-una-exposicion-que-aliviar-la-falta-de-agua-potable-en-choco/548152

Stapper, C. (2009). La regulación de los Servicios Públicos Domiciliarios: eficiencia y protección de los derechos de los usuarios. Una visión desde el sector de agua potable y saneamiento básico. Bogotá D.C: Comisión de Regulación de Agua Potable y Saneamiento Básico.

Superintendencia de Servicios Públicos Domiciliarios (2006). Control Social de los Servicios Públicos Domiciliarios. Módulo 6. Recuperado de https://www.funcionpublica.gov.co/eva/admon/files/empresas/ZW1wcmVzYV83Ng==/archivos/ 1454680233_34a1abc98c6388fb838335c837cc1c8e.pdf

Superintendencia de Servicios Públicos Domiciliarios (2009). Concepto Unificado 08.

Recuperado de https://www.superservicios.gov.co/normativa

Superintendencia de Industria y Comercio (2018). Por abusar de su posición de dominio en venta de agua en bloque con la intención de excluir a un competidor en el mercado de acueducto, Superindustria sanciona a la Empresa de Acueducto de Bogotá. Recuperado de http://www.sic.gov.co/por-abusar-de-su-posicion-de-dominio-en-venta-de-agua-en-bloque-conla-intencion-de-excluir-a-un-competidor-en-el-mercado-de-acueducto-superindustria-sanciona-ala-empresa-de-acueducto-de-bogota.

\section{Legislación}

Australia Government - Department of Agriculture and Water Resources (25 de junio de 2004). Intergovernmental Agreement on a National Water Initiative. Recuperado de http://www.agriculture.gov.au/water/policy/nwi

Congreso de la República de Colombia. (11 de julio de 1994). Por la cual se establece el régimen de los servicios públicos domiciliarios y se dictan otras disposiciones. [Ley 142 de 1994]. DO: 41433.

Congreso de la República de Colombia. (29 de diciembre de 1998). Por la cual se dictan normas sobre la organización y funcionamiento de las entidades del orden nacional. [Ley 489 de 1998]. DO: 43464.

Congreso de la República de Colombia (24 de julio de 2009). Ley por medio de la cual se dictan normas en materia de protección de la competencia. [Ley 1340 de 2009]. DO: 47.420 
Congreso de la República de Colombia. (18 de enero de 2011). Por la cual se expide el Código de Procedimiento Administrativo y de lo Contencioso Administrativo. [Ley 1437 de 2011]. DO: 47956.

Constitución Política de Colombia [Const.]. (1991) Ed. Legis

Departamento Nacional de Planeación. Consejo Nacional de Política Económica y Social (2 de octubre de 2014). Documento Conpes 3816 Mejora Normativa: Análisis de Impacto. Recuperado de https://www.minminas.gov.co/documents/10180/19764302/CONPES3816.pdf/5e09cddfad94-4b3f-9255-9548aab35a61

Departamento Nacional de Planeación. Consejo Nacional de Política Económica y Social (15 de marzo de 2018). Estrategia para la implementación de los Objetivos de Desarrollo Sostenible (ODS) en Colombia. Documentos CONPES 3918. Recuperado de https://colaboracion.dnp.gov.co/CDT/Conpes/Econ\%C3\%B3micos/3918.pdf

Gobierno de la República de Colombia. (24 de agosto de 2004). Por el cual se definen las reglas mínimas apra garantizar la divulgación y la participación en las actuaciones de las Comisiones de Regulación. [Decreto 2696 de 2004].

Gobierno de la República de Colombia. (26 de mayo de 2015). Por medio del cual se expide el Decreto Único Reglamentario del Sector, Vivienda, Ciudad y Territorio. [Decreto 1077 de 2015].

Ministerio de Vivienda, Ciudad y Territorio. (8 de junio de 2017). Reglamento Técnico para el Sector de Agua Potable y Saneamiento Básico (RAS). [Resolución 0330 de 2017].

Presidencia de la República de Colombia. (18 de diciembre de 1975). Por el cual se dicta el Código Nacional de Recursos Naturales Renovables y de Protección al Medio Ambiente. [Decreto Ley 2811 de 1974]. DO: 34243.

Presidencia de la República de Colombia. (13 de diciembre de 1999). Por el cual se reestructuran las Comisiones de Regulación y se dictan otras disposiciones. [Decreto 2474 de 1999].

Presidencia de la República de Colombia. (31 de julio de 2007). Por la cual se aprueban los estatutos y el Reglamento de la CRA. [Decreto 2882 de 2007].

Presidencia de la República de Colombia. (18 de febrero de 2015). Por el cual se crea la Comisión Interinstitucional de Alto Nivel para el alistamiento y la efectiva implementación de la Agenda de Desarrollo Post 2015 y sus Objetivos de Desarrollo Sostenible - ODS. [Decreto 280 de 2015].

Presidencia de la República Dominicana. (22 de febrero de 2016). Por la cual se crea la Comisión para el Desarrollo Sostenible. [Decreto 23 de 2016]. Recuperado de http://economia.gob.do/mepyd/wp-content/uploads/archivos/transparencia/base-legal/decreto-23160002.pdf 
Presidência da República no Brasil. (27 de octubre de 2016). Cria a Comissão Nacional para os Objetivos de Desenvolvimento Sustentável. [Decreto No. 8892 de 2016]. Recuperado de http://www.planalto.gov.br/ccivil_03/_ato2015-2018/2016/decreto/D8892.htm

\section{Jurisprudencia}

Consejo de Estado de Colombia, (17 de febrero de 2005), Auto Exp. 27673. [MP. Alier Hernández].

Corte Constitucional de Colombia, (17 de octubre de 2002), Sentencia T-881. [MP. Eduardo Montealegre Lynett].

Corte Constitucional de Colombia, (6 de agosto de 2009), Sentencia C-546. [MP. María Victoria Calle Correa]. 